\title{
Quality of Life in Patients with Chronic Heath Failure Followed at the Tertiary Hospitals of Sub-Saharan Africa
}

\author{
Jérôme Boombhi ${ }^{1,2, ~ *, ~ J e a n-P i e r r e ~ K a m g a ~}{ }^{1,3}$, Liliane Mfeukeu-Kuatét, ${ }^{1,}$, Delphine Kingue ${ }^{3}$, \\ Mazou Ngou Temgoua ${ }^{1}$, Alain Menanga ${ }^{1,2}$, Samuel Kingué ${ }^{1,2}$ \\ ${ }^{1}$ Department of Internal Medicine and Specialties, Faculty of Medicine and Biomedical Sciences, University of Yaoundé I, Yaoundé, \\ Cameroon \\ ${ }^{2}$ Cardiology Unit, Yaoundé General Hospital, Yaoundé, Cameroon \\ ${ }^{3}$ Psychiatric Unit, Jamot Yaoundé Hospital, Yaoundé, Cameroon \\ ${ }^{4}$ Cardiology Unit, Central Hospital of Yaoundé, Yaoundé, Cameroon
}

\section{Email address:}

boombhijerome@yahoo.fr (J. Boombhi), olen_cm@yahoo.fr (Jean-Pierre K.), mfeukeuliliane@yahoo.fr (L. Mfeukeu-Kuaté), tatikingue@yahoo.com (D. Kingue), neurotemgoua@yahoo.fr (M. N. Temgoua), amenanga@yahoo.fr (A. Menanga), samuel_kingue@yahoo.fr (S. Kingue)

${ }^{*}$ Corresponding author

\section{To cite this article:}

Jérôme Boombhi, Jean-Pierre Kamga, Liliane Mfeukeu-Kuaté, Delphine Kingue, Mazou Ngou Temgoua, Alain Menanga, Samuel Kingué. Quality of Life in Patients with Chronic Heath Failure Followed at the Tertiary Hospitals of Sub-Saharan Africa. Cardiology and Cardiovascular Research. Vol. 3, No. 4, 2019, pp. 80-85. doi: 10.11648/j.ccr.20190304.11

Received: May 14, 2019; Accepted: June 18, 2019; Published: September 25, 2019

\begin{abstract}
Heart Failure (HF) has become one of the most important chronic medical conditions worldwide. It's associated with high morbidity and mortality. Despite improving in patient's management, little works have been done to evaluate the quality of life of patients with heart failure in Sub-Saharan Africa. The objective of this work was to assess the quality of life of patients with Chronic Heart Failure (CHF) followed in three reference hospitals of Cameroon. We carried out a crosssectional study over a period of 04 months, from January to May 2017. The patients were recruited from the cardiology departments of three references Hospitals of Cameroon: Yaoundé Central Hospital (YCH), General Hospital of Yaoundé (GHY) and Yaoundé University Teaching Hospital (YUTH). We included all patients aged 18 years and above followed for $\mathrm{CHF}$ and consenting to participate in the study. Patients with other chronic conditions (chronic kidney disease, cancer, schizophrenia) were excluded. The quality of life was assessed using the Minnesota Living with Heart Failure tool (MLwHF). A total of 119 patients were recruited. The mean age was $66 \pm 13$ years. More than $2 / 3(70.6 \%)$ of the patients were unemployed. The majority of patients $(83.2 \%)$ had low monthly income $(<100000$ FCFA). Stage II of heart failure according to New York Heart Association (NYHA) was the most represented (50\%). The median scores for the Minnesota Living with Heart Failure Questionnaire (MLwHFQ) were generally low. The risk factors of poor life quality were: young age $(p=0.039)$, low educational attainment $(p=0.046)$, low monthly income $(p=0.024)$, exposure to tobacco $(p=0.005)$, low left ventricular ejection fraction $(p=0.003)$, mental depression $(p<0.001)$, anxiety $(p<0.001)$, non-adherence to treatment $(p=0.035)$. The only factors that remain significant after adjusting for confounders are: mental depression $(0,002)$ and functional class of NYHA $(<0,001)$. In conclusion, Quality of life is slightly affected in patients with chronic heath failure. The few proportion of alter quality of life is explained mostly by psychological and clinical factors. The clinician should pay attention to these factors for the better management of the patients in Sub-Saharan Africa.
\end{abstract}

Keywords: Quality of Life, Chronic Heart Failure, Tertiary Hospitals, Sub-Saharan Africa

\section{Introduction}

Chronic Heart Failure (CHF) is a global public health problem with high morbidity and mortality [1]. It affected 23 millions of people in the world and 5.8 millions of people in United States; In Europe the prevalence in general population 
varying between 0.4 to $2 \%[2,3]$. The burden in Sub-Saharan Africa is also high; in fact Heart failure accounts for over $30 \%$ of hospital admission in specialized cardiovascular units and $3 \%$ to $7 \%$ in general internal medicine [4]. CHF is associated with physical, social, psychological complications that affected quality of life which increase the rate of repeat hospitalization and mortality [5]. World Health Organization (WHO) has defined Quality of life (QOL) as "an individual's perception of their position in life in the context of the culture and value systems in which they live and in relation to their goals, expectations, standards, and concerns" [6]. The global prevalence of alter quality of life in CHF is not well describe in the literature because of the heterogeneity of clinical tools of assessment, but among the predictive factors of poor QOL the major determinant is severity of heart failure evaluate by functional NYHA class" $[6,7]$. Systematic evaluation of QOL in patient with CHF could help to reduce the burden in this population. In Sub-Saharan Africa there is no sufficient data which can be address to the health policy; this fact justified the current study to assess the quality of life of patients with chronic heart failure (CHF) followed in three reference hospitals of Cameroon.

\section{Material and Methods}

\subsection{Study Design, Setting and Participants}

We carried out a cross-sectional study over a period of 04 months, from January to May 2017. The patients were recruited from the cardiology departments of three references Hospitals of Cameroon: Yaoundé Central Hospital (YCH), General Hospital of Yaoundé (GHY) and Yaoundé University Teaching Hospital (YUTH). We included all patients aged 18 years and above followed for $\mathrm{CHF}$ and consenting to participate in the study. Patients with other chronic conditions (chronic kidney disease, cancer, schizophrenia) and those with incomplete file were excluded. Sample size calculation was done by Cochrane formula [8]:

$$
N=\frac{Z^{2} x P(1-p)}{d^{2}}=85 \text { patients }
$$

$\mathrm{N}$ : minimal sample size.

Z: 1.96 for an alpha error of $5 \%$.

P: 0.3 (Prevalence of heart failure in Cameroon found by KINGUE et al in 2004) [9].

D: precision set as $10 \%$.

\subsection{Data Collection}

Using a structured pilot-tested questionnaire, we briefly interviewed all attended patients in external consultation unit of cardiology department. We collected following sociodemographic data: sex, age, matrimonial status, level of education, ethnic origin, religion, profession, monthly income, and monthly cost of health care and existence of medical insurance. Clinical data concerned: Cardiovascular risk factors such as history of alcohol or tobacco consumption, sedentary lifestyle, obesity defined as a body mass index $\geq 30 \mathrm{~kg} / \mathrm{m}^{2}$, dyslipidemia, hereditary exposure, duration and etiologies of chronic health failure, weight, height, body mass index. Severity of heart failure was assessed using the functional class of New York Heart Association (NYHA). The Left Ventricular Ejection Fraction (LVEF) was determining by transthoracic cardiac ultrasonography by using either Teicholz or Simplify Simpson's formula. Therapeutic data concerned current drugs for heart failure, side effect and compliance. The adherence to treatment was evaluated by Gired questionnaire [10]. Finally, quality of life was assessed by a validated tool: Minnesota Living with Heart Failure (MLHwFQ) which analyzes QOL during the last 4 weeks. The MLHFQ is a self-administered disease-specific questionnaire for patients with $\mathrm{HF}$, comprising 21 items rated on six-point Likert scales, representing different degrees of impact of HF on HRQoL, from 0 (none) to 5 (very much). It provides a total score (range $0-105$, from best to worst HRQoL), as well as scores for two dimensions, physical (8 items, range 0-40) and emotional (5 items, range 0-25). The maximum score of 105 express as very limited in performing all physical activities, very depressed, tired, with a strong feeling of being a burden to others [11].

\subsection{Statistical Analyses}

Data were analysed using SPSS version 23.0. Means (standard deviations), medians, interquartile range (IQR) were used to summarize continuous variables, while frequencies and proportions were calculated for categorical variables. Mann Whitney and Kruskal Wallis were used to compare medians. The correlation between value of the MLHwFQ score and independent variables were done using linear regression. The statistical significance was set at $5 \%$.

\section{Results}

\subsection{Characteristics of the Study Participants}

A total of 119 patients were recruited with female predominance $(n=68 ; 58 \%)$, Figure 1 . The mean age was $66 \pm$ 13 years with range of 20 to 94 years. More than $2 / 3(70.6 \%)$ of the patients were unemployed. The majority of patients (83.2\%) had low monthly income ( $<100000$ FCFA) (Table 1$)$. Hypertension was the major co-morbidity and Stage II of heart failure according to New York Heart Association (NYHA) was the most represented (50\%). There were approximately the same proportions of all type of heart failure according to the left ventricular ejection fraction (Table 2).

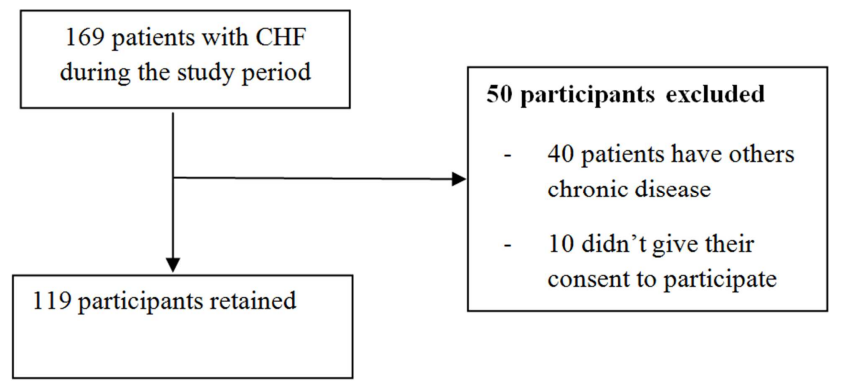

Figure 1. Flow chart of the participants. 
Table 1. Demographical and socio-economical characteristics of participants.

\begin{tabular}{llll}
\hline Variables & & Effective $(\mathbf{n}=\mathbf{1 1 9})$ & Percentage (\%) \\
\hline \multirow{2}{*}{ Sex } & Female & 71 & 59.7 \\
& Male & 48 & 40.3 \\
Matrimonial status & Married & 59 & 49.6 \\
& Non Married & 60 & 50.4 \\
& Non scolarise & 28 & 23.5 \\
Level of education & Primary & 46 & 38.7 \\
& Secondary & 32 & 26.9 \\
\multirow{4}{*}{ Occupation } & University & 13 & 10.9 \\
& Employed & 67 & 56.3 \\
Monthly salary & Unemployed & 52 & 43.7 \\
& $\geq 100000$ & 20 & 16.8 \\
\hline
\end{tabular}

Table 2. Clinical and paraclinical characteristics of the population.

\begin{tabular}{llll}
\hline Variables & & Effective $(\mathbf{n}=\mathbf{1 1 9})$ & Percentage (\%) \\
\hline & Hypertension & 78 & 65.5 \\
& Diabetes & 10 & 8.4 \\
& Obesity & 21 & 17.6 \\
Co-morbid conditions & Dyslipidemia & 10 & 8.4 \\
& Cachexia & 3 & 2.5 \\
& Tobacco consumption & 3 & 2.5 \\
& Alcohol absuse & 21 & 17.6 \\
& Hypertensive heart disease & 58 & 48.7 \\
Myocardiopathy & 30 & 25.2 \\
Etiologies of CHF & Valvulopathy & 22 & 18.5 \\
& Ischemic heart disease & 11 & 9.2 \\
& Others & 4 & 2.4 \\
& I & 40 & 33.6 \\
NYHA class & II & 60 & 50.4 \\
& III & 17 & 14.3 \\
& IV & 2 & 1.7 \\
LVEF & Preserved & 42 & 35.3 \\
& Mid-range & 37 & 31.1 \\
& Altered & 40 & 33.6 \\
Adherence to treatment & Non adherence & 14 & 11.8 \\
& Low adherence & 62 & 56 \\
& Good adherence & 43 & 36 \\
\hline
\end{tabular}

\subsection{Assessment of Quality of Life}

The median scores for the Minnesota Living with Heart Failure Questionnaire (MLwHFQ) were generally low with a median score of $22(11-42)$ in this population. Both physical and emotional dimension are concerned (Table 3$)$.

Table 3. Repartition of the population according to the MLwHF score.

\begin{tabular}{llll}
\hline Component & Mediane (IQR) & Minimum & Maximum \\
\hline Physical evaluation & $9(1-19)$ & 0 & 35 \\
Emotional evaluation & $8(4-15)$ & 0 & 24 \\
Total score & $22(11-42)$ & 0 & 73 \\
\hline
\end{tabular}

MLwHF: Minnesota Living with Heart Failure IQR: Interquartile Range.

\subsection{Factors Associated with Quality of Life}

In univariate analysis, the risk factors of poor life quality were: young age $(p=0.039)$, low educational attainment $(p=0.046)$, low monthly income $(\mathrm{p}=0.024)$, exposure to tobacco $(\mathrm{p}=$
$0.005)$, low left ventricular ejection fraction $(\mathrm{p}=0.003)$, anxiety $(p<0.001)$ and non-adherence to treatment $(p=0.035)$ Table 4. Functional class of NYHA $(<0,001)$ and mental depression $(p$ $<0.001)$ were the factors which remain significant after adjusting for confounders (Figures 2, 3 and Table 5). 


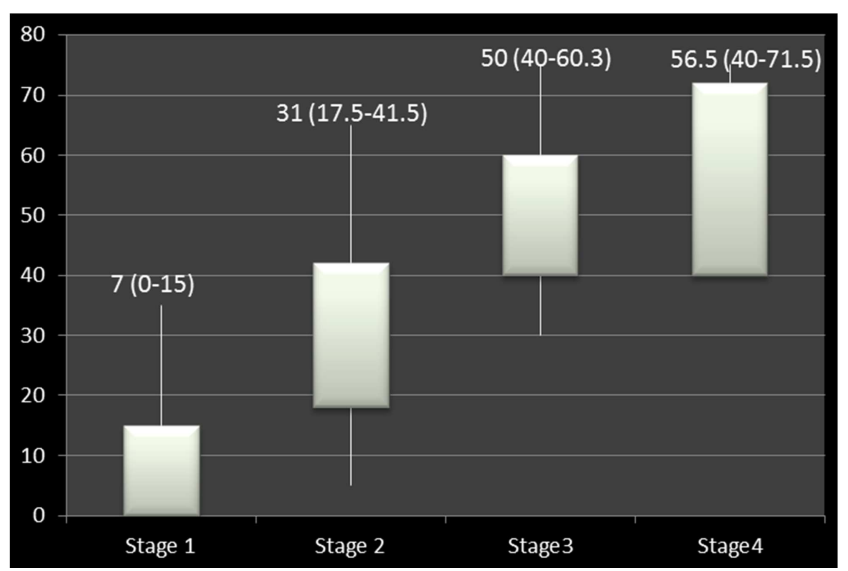

Figure 2. Comparison of the median score of MLwHF according to NYHA class.

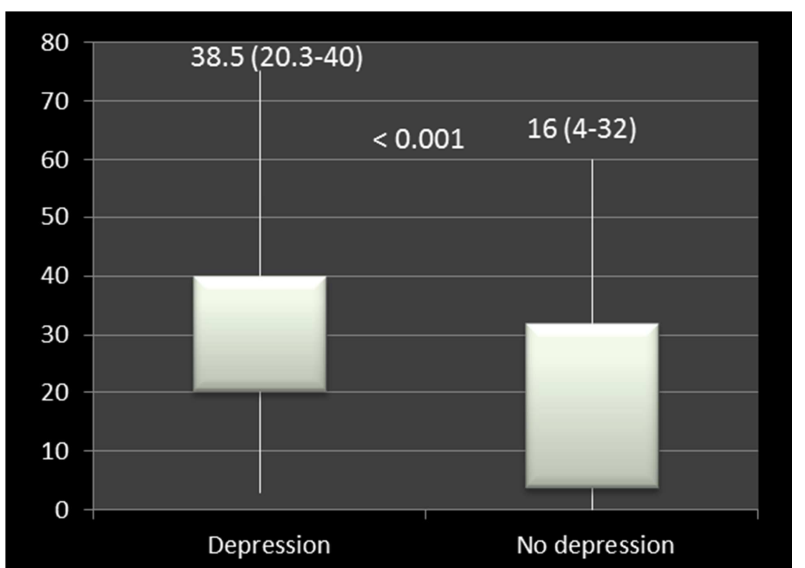

Figure 3. Comparison of median score of MLwHF according to depression status.

Table 4. Factors associated with quality of life in univariate analysis.

\begin{tabular}{|c|c|c|c|}
\hline Variable & Physical component & Emotional component & Total of MLwHFQ score \\
\hline \multicolumn{4}{|l|}{ Sex } \\
\hline Female & $8(0-16.5)$ & $8(3.5-15)$ & $21(7.5-41)$ \\
\hline Male & $10.5(4-21)$ & $8(4-14)$ & $23.5(14-47)$ \\
\hline$P$ value & 0.220 & 0.897 & 0.205 \\
\hline \multicolumn{4}{|l|}{ Age } \\
\hline$<68$ & $11(4-21)$ & $8.5(4-15)$ & $31(12-51)$ \\
\hline$P$ value & 0.039 & 0.265 & 0.016 \\
\hline \multicolumn{4}{|l|}{ Level of education } \\
\hline Primary/non scolarised & $8(0-16)$ & $8(4-15)$ & $19.5(7-39)$ \\
\hline Secondary & $13(6-23)$ & $9.5(4-16)$ & $31.5(14.5-51)$ \\
\hline University & $8(2-16)$ & $6(2-11)$ & $16(12-35.5)$ \\
\hline$P$ value & 0.046 & 0.437 & 0.134 \\
\hline \multicolumn{4}{|l|}{ Monthly income } \\
\hline$\geq 100000$ & $8(1-16)$ & $6.5(2-11.5)$ & $18(13-35)$ \\
\hline$P$ value & 0.392 & 0.024 & 0.089 \\
\hline \multicolumn{4}{|l|}{ Matrimonial status } \\
\hline Married & $11(3-21)$ & $8(4-14)$ & $25(12-47)$ \\
\hline Non married & $8(0-16)$ & $8(0-16)$ & $18(8.5-39)$ \\
\hline$P$ value & 0.182 & 0.727 & 0.228 \\
\hline \multicolumn{4}{|l|}{ Obesity } \\
\hline Yes & $15(1-17.5)$ & $8(4-14)$ & $30(8-42)$ \\
\hline No & $9(1-19)$ & $8(4-15)$ & $21.5(11-42.5)$ \\
\hline$P$ value & 0.760 & 0.772 & 0.972 \\
\hline \multicolumn{4}{|l|}{ Tobacco consumption } \\
\hline Yes & $7(0-13)$ & $18(8-24)$ & $23(11-43)$ \\
\hline No & $9(1-19)$ & $6(4-11)$ & $19(4-32)$ \\
\hline$P$ value & 0.905 & 0.005 & 0.647 \\
\hline Non Ischemic heart disease & $9(1-19)$ & $8(4-15)$ & $21(10-43)$ \\
\hline$P$ value & 0.937 & 0.639 & 0.572 \\
\hline \multicolumn{4}{|l|}{ LVEF } \\
\hline$\geq 45 \%$ & $14(5-21)$ & $10(4-16)$ & $33(14-50)$ \\
\hline$<45 \%$ & $6(0-13)$ & $6(3-13.5)$ & $16(8-33.5)$ \\
\hline \multicolumn{4}{|l|}{ Adherence to treatment } \\
\hline Yes & $5(1-11)$ & $6(4-12)$ & $18(7-34)$ \\
\hline No & $11(1-21)$ & $8(4-16)$ & $36(11-49)$ \\
\hline $\mathrm{P}$ value & 0.035 & 0.105 & 0.015 \\
\hline
\end{tabular}


Table 5. Factors associated with quality of life in multivariate analysis.

\begin{tabular}{lll}
\hline \multirow{2}{*}{ Independent variable } & \multicolumn{2}{l}{ Total MLwHFQ score } \\
\cline { 2 - 3 } & $\mathbf{B}$ & P value \\
\hline Age & -0.047 & 0.650 \\
Level of education & 0.101 & 0.342 \\
Monthly income & 0.012 & 0.901 \\
Tobacco exposure & 0.092 & 0.324 \\
NYHA stage & 0.595 & $<0,001$ \\
LVEF & -0.078 & 0.567 \\
Mental depression & -0.363 & 0.002 \\
Anxiety & -0.081 & 0.370 \\
Adherence to treatment & -0.189 & 0.061 \\
\hline
\end{tabular}

\section{Discussion}

Like many chronic disease, chronic heath failure is associated with poor quality of life. This is strongly related to the stage of the disease and some socioeconomic factors [5]. The best tool validate to assess QOL in CHF is the MLwHFQ [11]. Through this tool we have try to describe the quality of life of Cameroonian CHF patient in order to reduce mortality in this population. The quality of life in this population was better comparing to previous studies done [12-14]. This finding can be explained by the fact that many patients were in stage II functional class of NYHA, knowing that severe alteration of functional status is associated with poor quality of life. Another explanation is that the mean age of population was 66 years; in sub Saharan Africa it is rare to reach this age, therefore patients could consider some alteration of their health as normal for the age and therefore reduce the psychological burden.

Potential socio-economic factors of poor life quality found in this study are: young age, low educational attainment, monthly income, these finding are well described in the literature [15-16]. In fact, young people have many projects in their life and the disease constitutes a barrier to realize their objectives so they could develop psychological problem which may alter quality of life. Low financial resources are also a great component of poor quality of life by reducing access to health care like demonstrate a several studies [17]. This lack of money with psychological problem can also explain non-adherence to treatment which are found as a determinant of QOL.

After adjusting for all confounding factors we realized that only functional class of NYHA and depression were linked to the quality of life. This finding is similar to previous studies, $[13,16,18-21]$. In fact with permanent dyspnea patients are unable to work and lost their autonomy which contributes to alter their life quality. In the same extend this lost of autonomy can result to depression which further aggravate the disease. In order to improve quality of life we have to reduce progression of the disease to severe functional class and screening all CHF patients for depression.

\section{Conclusion}

Quality of life of CHF patient in Cameroon is relatively better than other population. Some cultural factors may explain this finding. For those who have poor life quality, the major determinants are severity of the disease and depression. Knowing that it is sometimes difficult to reduce de progression of the disease in all patients, it is important to screen all CHF patients for depression in order to give better quality of life to this patient.

\section{List of Abbreviations}

$\begin{array}{ll}\text { CHF } & \text { Chronic Heart Failure } \\ \text { GHY } & \text { General Hospital of Yaoundé } \\ \text { HF } & \text { Heart Failure } \\ \text { IQR } & \text { Interquartile Range } \\ \text { LVEF } & \text { Left Ventricular Ejection Fraction } \\ \text { MLHwFQ } & \text { Minnesota Living with Heart Failure } \\ \text { NYHA } & \text { New York Heart Association } \\ \text { QOL } & \text { Quality of Life } \\ \text { SPSS } & \text { Statistical Package for Social Sciences } \\ \text { WHO } & \text { World Health Organization } \\ \text { YUTH } & \text { Yaoundé University Teaching Hospital }\end{array}$

\section{Declarations}

Ethics approval and consent to participate: Ethical approval was obtained from the Institutional Review Board of the Faculty of Medicine and Biomedical Sciences, University of Yaoundé I. Also, administrative authorization was obtained from the Directors of the General Hospital of Yaoundé, Central Hospital of Yaoundé and Yaoundé University Teaching Center prior to the start of the study. Written informed consent was obtained from all study participants who part took in this study.

\section{Availability of Data and Materials}

The datasets used and analyzed during the current study are available from the corresponding author on reasonable request.

\section{Competing Interests}

The authors declare that they have no competing interests.

\section{Authors' Contributions}

JB, JPOK, LMK, DE, AM and SK: study conception and 
design, data collection and analysis, interpretation of results. Manuscript writing and critical revision: JB, MT. All the authors read and approved the final version of the manuscript.

\section{Acknowledgements}

We would like to acknowledge the study participants for their commitment. The authors equally thank the administrative authorities of the Yaoundé General Hospital, Central Hospital of Yaoundé and Yaoundé University Teaching Center for granting them authorization to carry out this study.

\section{References}

[1] Rustoen T, Stubhaug A, Eidsmo I, Westheim A, Paul SM, Miaskowski C. Pain and Quality of Life in Hospitalized Patients with Heart Failure. J Pain Symptom Manage. 2008; 36 (5): 497-504.

[2] AbuRuz ME, Alaloul F, Saifan A, Masa'Deh R, Abusalem S. Quality of Life for Saudi Patients with Heart Failure: A CrossSectional Correlational Study. Glob J Health Sci. 2016; 8 (3): 49-58.

[3] Jondeau G. Insuffisance cardiaque et cardiomyopathies. Arch Mal Coeur Vaiss. 2006; 99 (2): 3-79.

[4] Kengne AP, Dzudie A, Sobngwi E. Heart failure in subSaharan Africa: A literature review with emphasis on individuals with diabetes. Vascular Health and Risk Management 2008: 4 (1) 123-130.

[5] Iqbal J, Francis L, Reid J, Murray S, Denvir M. Quality of life in patients with chronic heart failure and their carers: a 3-year follow-up study assessing hospitalization and mortality. Eur J Heart Fail. 2010 Sep; 12 (9): 1002-8. doi: 10. 1093/eurjhf/hfq114. Epub 2010 Jul 8.

[6] Adebayo SO, Olunuga TO, Durodola A, Ogah OS. Quality of life in heart failure: A review. Nig J Cardiol 2017; 14: 1-8.

[7] Gonzalez DG. The Effects of Congestive Heart Failure on Quality of Life: As Evaluated by the Minnesota Living with Heart Failure Questionnaire [The Eleanor Mann School of Nursing Undergraduate Honors Theses]. University of Arkansas, Fayetteville; 2016.

[8] Cochran WG. Sampling Theory When the Sampling-Units are of Unequal Sizes. J Am Stat Assoc. 1942; 37 (218): 199-212.

[9] Kingue S, Dzudie A, Menanga A, Akono M, Ouankou M, Muna W. Nouveau regard sur l'insuffisance cardiaque chronique de l'adulte en Afrique à l'ère de l'échocardiographie Doppler: expérience du service de médecine de l'Hôpital Général de Yaoundé. Ann Cardiol Angéiologie. 2005; 54 (5): 276-8.

[10] Pio M, Baragou S, Afassinou Y, Pessinaba S, Atta B, Ehlan K, et al. Observance thérapeutique de l'hypertension artérielle et ses facteurs dans le service de cardiologie du CHU Tokoin de Lomé. Pan Afr Med J. 2013; 14: 11-19.

[11] Bilbao A, Escobar A, García-Perez L, Navarro G, Quirós R. The Minnesota living with heart failure questionnaire: comparison of different factor structures. Health and Quality of Life Outcomes (2016) 14: 23.

[12] Britz JA, Dunn KS. Self-care and quality of life among patients with heart failure. J Am Acad Nurse Pract. 2010; 22 (9): 480-7.

[13] Chu SH, Lee WH, Yoo JS, Kim SS, Ko IS, Oh EG, et al. Factors affecting quality of life inKorean patients with chronic heart failure. J Nurs Sci JJNS. 2014; 11 (1): 54-64.

[14] Mbakwem AC, Aina FO, Amadi CE, Akinbode AA, Mokwunyei J. Comparative analysis of the quality of life of heart failure patients in South Western Nigeria. World J Cardiovasc Dis. 2013; 03 (01): 146-70.

[15] Masoudi FA, Rumsfeld JS, Havranek EP, House JA, Peterson $\mathrm{ED}$, Krumholz HM, et al. Age, functional capacity, and health-related quality of life in patients with heart failure. $\mathrm{J}$ Card Fail. 2004; 10 (5): 368-73.

[16] N'cho-mottoh MP, Coulibaly I, Yahehd K, Boka B, Bambakamagate D, Sow-toure M. Facteurs prédictifs de la qualité de vie de l'insuffisant cardiaque noir africain. Médecine Afr Noire. 2015; 62 (11): 541-6.

[17] Shih ML, Chen HM, Chou FH, Huang YF, Lu CH, Chien HC. [Quality of life and associated factors in patients with heart failure]. Hu Li Za Zhi. 2010; 57 (6): 61-71.

[18] Gott M, Barnes S, Parker C, Payne S, Seamark D, Gariballa S, et al. Predictors of the quality of life of older people with heart failure recruited from primary care. Age Ageing. 2006; 35 (2): $172-7$.

[19] Huang TY, Moser DK, Hwang SL, Lennie TA, Chung M, Heo S. Comparison of HealthRelated Quality of Life Between American and Taiwanese Heart Failure Patients. J Transcult Nurs. 2010; 21 (3): 212-9.

[20] Loo DWY, Jiang Y, Koh KWL, Lim FP, Wang W. Selfefficacy and depression predicting the health-related quality of life of outpatients with chronic heart failure in Singapore. Appl Nurs Res. 2016; 32: 148-55.

[21] Lee DT, Yu DS, Woo J, Thompson DR. Health-related quality of life in patients with congestive heart failure. Eur J Heart Fail. 2005; 7 (3): 419-22. 